DOI 10.37882/2223-2982.2022.01.37

\title{
ОСОБЫЕ ОБРАЗОВАТЕЛЬНЫЕ ТЕХНОЛОГИИ СОВРЕМЕННОГО ВУЗА
}

\section{SPECIAL EDUCATIONAL TECHNOLOGIES OF A MODERN UNIVERSITY \\ D. Tsekhanovich}

Summary: Modern education in Russia is undergoing significant changes caused by the urgent need of society for a well-trained specialist, professional and full-fledged member. The task of education is to prepare such a specialist, a person, to release him into life, and in most cases accompany his professional development at all levels of his activity. Under such conditions, the problem of lagging the pace of increasing the quality of training of a modern specialist at a university from the constantly increasing modern requirements of society in the face of employers is quite obvious. Basically, the tightening requirements are justified by the general technological progress, the specifics and the increasing volume of activities, the efficiency of labor, and increasing competitiveness. The author of the article suggests that a particular problem lies in the insufficient degree of involvement by teachers in universities of modern, innovative and even non-standard, individual educational technologies of teaching, which leads to an increase in this lag.

Drawing the reader's attention to the problem posed, the author himself proposes to consider some examples of modern educational technologies, recommended in a number of universities in the country, as significantly effective, contributing to the educational and professional development of the student. The technologies proposed for consideration are personality-oriented and aimed, first of all, at the predominant independent advancement of the student in the development of new knowledge. The implementation of these technologies makes it possible to reduce the lag between the theory of student learning and the practice of a specialist's life.

The uniqueness of the article is due to the fact that some of the technologies considered in the article were formed by the author of the article himself.

Keywords: higher school, distance learning, modern university, educational process, presentation film, handouts, teaching technology, automated workplace, interactive learning, pedagogical process.
$\mathrm{T}$ ребования современного общества к выпускнику ВУЗа, выраженные Государственными образовательными стандартами нового поколения в значительной мере повышают ответственность всего управленческого персонала ВУЗа, в общем, и педагога, в частности, в качестве разрабатываемых рабочих программ и продуктивности взаимодействия со студентом. С другой стороны, этими же стандартами заметно расширены возможности ВУЗов и их преподавателей в достижении эффективности образовательных процессов.
Цеханович Денис Борисович

преподаватель, Московское высшее общевойсковое командное училище; аспирант, Московский педагогический государственный университет komandor7932@mail.ru

Аннотация: Современное образование в России претерпевает значительные изменения, вызванные острой потребностью общества в качественно подготовленном специалисте, профессионале и полноценном его члене. Задача образования - подготовить такого специалиста, человека, выпустить его в жизнь, а в большинстве случаев и сопровождать его профессиональное становление на всех уровнях его деятельности.

В таких условиях в достаточной степени очевидной является проблема отставания темпов наращивания качества подготовки современного специалиста в ВУЗе от постоянно возрастающих современных требований общества в лице работодателей. В своей основе ужесточающиеся требования обоснованы всеобщим технологическим прогрессом, спецификой и увеличивающимся объемом деятельности, оперативности труда, возрастающей конкурентности. Автор статьи предполагает, что частная проблема кроется в недостаточной степени задействования преподавателями в ВУЗах современных, инновационных и даже нестандартных, индивидуальных образовательных технологий обучения, что и приводит к увеличению этого отставания. Обращая внимание читателя на поставленную проблему, сам автор предлагает к рассмотрению некоторые примеры современных образовательных технологий, зарекомендованных в ряде ВУЗов страны, как значительно эффективных, способствующих учебно-профессиональному развитию студента. Предлагаемые к рассмотрению технологии личностно-ориентированы и направленны, в первую очередь, на преобладающее самостоятельное продвижение студента в освоении нового знания. Реализация этих технологий позволяет сократить отставание теории обучения студента от практики жизни специалиста.

Уникальность статьи обусловлена тем, что некоторые из рассматриваемых в статье технологий формировались самим автором статьи.

Ключевые слова: высшая школа, дистанционное обучение, современный ВУ3, учебный процесс, презентационный фильм, раздаточный материал, технология обучения, автоматизированное рабочее место, интерактивное обучение, педагогический процесс.

Облик подготавливаемого ВУЗом специалиста остался практически неизменным - он по-прежнему должен быть конкурентно способным и обладающим в полной мере соответствующими своей специальности компетенциями, он должен быть и достойным членом общества.

Естественно, что в таких условиях особое, значительно большее внимание многих исследователей привлек к себе феномен познавательного процесса студента в 
ходе его обучения в ВУЗе.

Многие современные преподаватели сходятся во мнении о том, что успех в повышении качества подготовки современного специалиста в ВУЗе во многом зависит от самостоятельной работы и способности к таковой вообще самого обучающегося в ВУЗе. Именно этот аспект автор и принял в статье за основу, раскрывающую комплексную образовательную технологию, уже применяемую в некоторых современных ВУЗах.

Задача современного преподавателя, с точки зрения автора, состоит в том, что бы студент был обеспечен соответствующими новым стандартам условиями эффективной учебно-познавательной деятельности, среди которых наиболее актуальными, по мнению же автора, следует считать: эффективное управление самостоятельной подготовкой студентов вне занятий (с привлечением ресурсов образовательной среды ВУЗа); разработка, внедрение и применение в ходе занятий новых учебных и учебно-методических пособий, обязательное их интегрирование в образовательную среду ВУЗа; формирование личностно-ориентированного взаимодействия со студентом, основанного на оперативности учебного сотрудничества и творческом подходе к освоению обучающимися информации. Сегодня в мире, пожалуй, самым активным и жестоким законодателем во всех без исключения смыслах и сферах деятельности человечества явился коронавирус Covid-19, носящий характер пандемии. Именно он установил обязательную необходимость в формировании в образовании условий, позволяющих быстро и без снижения интенсивности переформатировать учебный процесс ВУЗа на дистанционные формы обучения студентов.

Не последнее место в новых ФГОС отведено использованию особых методов обучения. Теперь стандарты предполагают, а в некоторых случаях навязывают педагогам высшей школы применение инновационных, интерактивных, технических и даже управленческих решений в образовательных технологиях, применяемых в вУЗе.

Рассмотрение образовательных технологий современного ВУЗа следует начать с условий их реализации, задействования и здесь в первую же, по мнению автора, очередь необходимо указать на дистанционное обучение - некий современный тренд в образовании, фон учебного процесса всех современных ВУЗов.

Дистанционное обучение - это современная и стремительно развивающаяся форма обучения, в том числе и студентов в ВУЗах. На сегодняшний день, дистанционное обучение достаточно востребовано на всех уровнях образования, оно становиться в один ряд с уже привычными и достаточно понятными нам очной и заочной формами. Но именно дистанционная форма обучения в наибольшей степени порождает новые, инновацион- ные, а порой и уникальные образовательные технологии обучения студентов в современном ВУЗе. Яркими тому примерами можно считать: организацию внутренних закрытых локальных и нелокальных сетей для обмена информацией, широкое применение особых презентационных форматов и видеофильмов, задействование на занятиях систем видеоконтроля, использование систем, в том числе и мобильных, опроса и голосования, задействование программ компьютерного моделирования и имитации и многие другие. Расставляя точки над «И», автор акцентирует внимание читателя на том, что дистанционное обучение в современной трактовке следует рассматривать как обучение при отсутствии только лишь непосредственного контакта педагога со студентом, т.е. присутствие субъекта педагогического процесса может быть условным - на мониторе автоматизированного рабочего места студента или же, вообще, только т.н. аудио присутствие (слышна только речь преподавателя (студента)). Такое присутствие может быть, как в online-, так и в offline-формате. Главное в этом контексте понимать, что управленческая деятельность преподавателя обязательна и совершенно не важно, в каком режиме времени.

Говоря о реализации дистанционной формы обучения студентов преподавателем, необходимо отметить, что он осуществляет свою деятельность одновременно в нескольких видах:

- коммуникативная деятельность преподавателя крайне важный вид труда, предполагающий его способности по эффективному вовлечению в процесс занятия студентов и удержания их внимания на необходимом уровне, что, по вполне понятным причинам, достаточно не просто;

- организующая деятельность преподавателя - не менее ответственный и сложный вид труда педагога, требующий оказания помощи обучающимся в освоении коммуникационных платформ сети Интернет, образовательных платформ и программ;

- учебная деятельность преподавателя - предполагающая специфичность в обучении студента на социальном расстоянии;

- координационная деятельность преподавателя - учитывающая необходимость преподавателя соорганизовать взаимодействие студентов с другими преподавателями, осуществляющими образовательную программу;

- контролирующая деятельность преподавателя особые способности преподавателя осуществлять контрольно-оценочные функции.

Компетенции педагога в таких условиях тоже становятся многогранны - теперь они предполагают его компетентности, как в собственной дисциплине, так и в современных технологиях обучения, интернет- и других сетевых технологиях. Необходимо и умение разбираться 
в вопросах мониторинга, организации и управления подобными дистанционными видами занятий.

Функциональный потенциал такой формы обучения так же заслуживает внимания. Индивидуальный темп обучения - ориентированный на личность студента. Оперативное взаимодействие всех участников образовательного процесса, в том числе и с третьими лицами руководителями организаций и учреждений в интересах которых готовятся специалисты. Большой объем доступной информации, степень структурирования которого может определять сам обучающийся. Бо́льшие возможности студентов по участию в конференциях, проектах, конкурсах и олимпиадах разного уровня и статуса.

Прогрессивное развитие общества, технологий и коммуникаций в нем, пандемия и все более возрастающие требования социального заказа закрепили и, безусловно, усилили значение и актуальность такого способа организации учебного процесса, как интерактивное обучение, все чаще выступающее в форме учебного взаимодействия, обучающегося с компьютером, при обязательном участии преподавателя. Вполне очевидно, что под компьютером понимается весь обучающий ресурс образовательной среды ВУЗа с его электронными библиотеками, учебными видеофильмами, базис-тестами, презентационными архивами, обучающими платформами, электронными тренажерами и пр.

Преподаватель при таком способе организации учебного процесса влияет на студента через его побуждение на творческое и, самое главное, самостоятельное осваивание информации, конечно же, это и поощрение его инициативы; важной является и консультация студента по наиболее сложным вопросам темы. Не менее важной в такой ситуации остается и контрольно-оценочная деятельность педагога [1, с. 66].

Внедрение этого способа организации обучения можно считать без преувеличения перспективным путем повышения эффективности подготовки будущих специалистов к профессиональной деятельности. Многие инновации в области образования сегодня связаны именно с внедрением интерактивности в обучении.

Совсем недавно в высшей школе безоговорочно преобладала такая форма обучения как лекция, посредством которой передаются знания, но не формируются умения. Лекция и сейчас пока что занимает ведущее место в обучении, однако все более активно осуществляется ее переход к компьютерным технологиям обучения. Такой процесс, конечно же, следует отметить, как благоприятствующий усвоению студентами новой информации.

Среди множества образовательных технологий, применяемых преподавателями в высшей школе и претендующих на статус современных, автор явно выделяет технологию, разработанную им, являющуюся комплексной образовательной технологией, и нашедшей свою реализацию в ряде ВУЗов страны.

Речь пойдет о современной и в достаточной мере прогрессивной образовательной технологии, объединяющей в себе дистанционные и интерактивные формы обучения, лекционную направленность и ориентацию на самостоятельный поиск информации студентом.

SHA-технология представляет из себя подготовленный особым образом презентационный фильм, ориентированный на восприятие обучающимися материала тремя путями: зрением, на слух и аналитически (см. схемy 1).

Такой презентационный фильм ориентирован на самостоятельную работу студента под руководством преподавателя. Темп этого фильма и вид его насыщения материалом выбирает в ходе занятия сам студент исходя из наиболее удобных для него способов восприятия информации. Насыщение презентации реализуется подробным видео, аудио и текстовым материалом на слайдах, обязательно сопровождающийся анимационными эффектами.

Для структуризации и приведения интересных и подтверждающих фактов по теме материала применяются гиперссылки на необходимую информацию в учебниках и учебных пособиях электронных библиотек, электронные сборники задач и ситуаций, базы данных, условия деятельности организаций и учреждений, в интересах которых готовятся специалисты. Ссылки могут раскрывать студенту и новостные интернет порталы. Особым образом предлагается к рассмотрению обучающимися и статистика по тематике занятия.

Автор обращает внимание читателя на некоторые особенности такой образовательной технологии, отличающей ее от программированного обучения. Таких особенностей несколько.

В первую очередь следует отметить более расширенные возможности SHA-технологии по визуализации материала с помощью мультимедийных средств. Здесь имеется ввиду технология видеомаппинга - проецирование слайда с презентации непосредственно на объект изучения, его расположение, макет или плакат. Это и программные технологии гипертекста, мульти- и гипермедиа, системы «виртуальной реальности». Это и задействование информационных телекоммуникационных сетей, в том числе и локальных. Такие видео технологии значительно повышают качество усвоения материала, способствуют формированию у студентов системного мышления, выделяют в содержании материала наиболее существенные его элементы.

Особая техническая подача и формированность пре- 


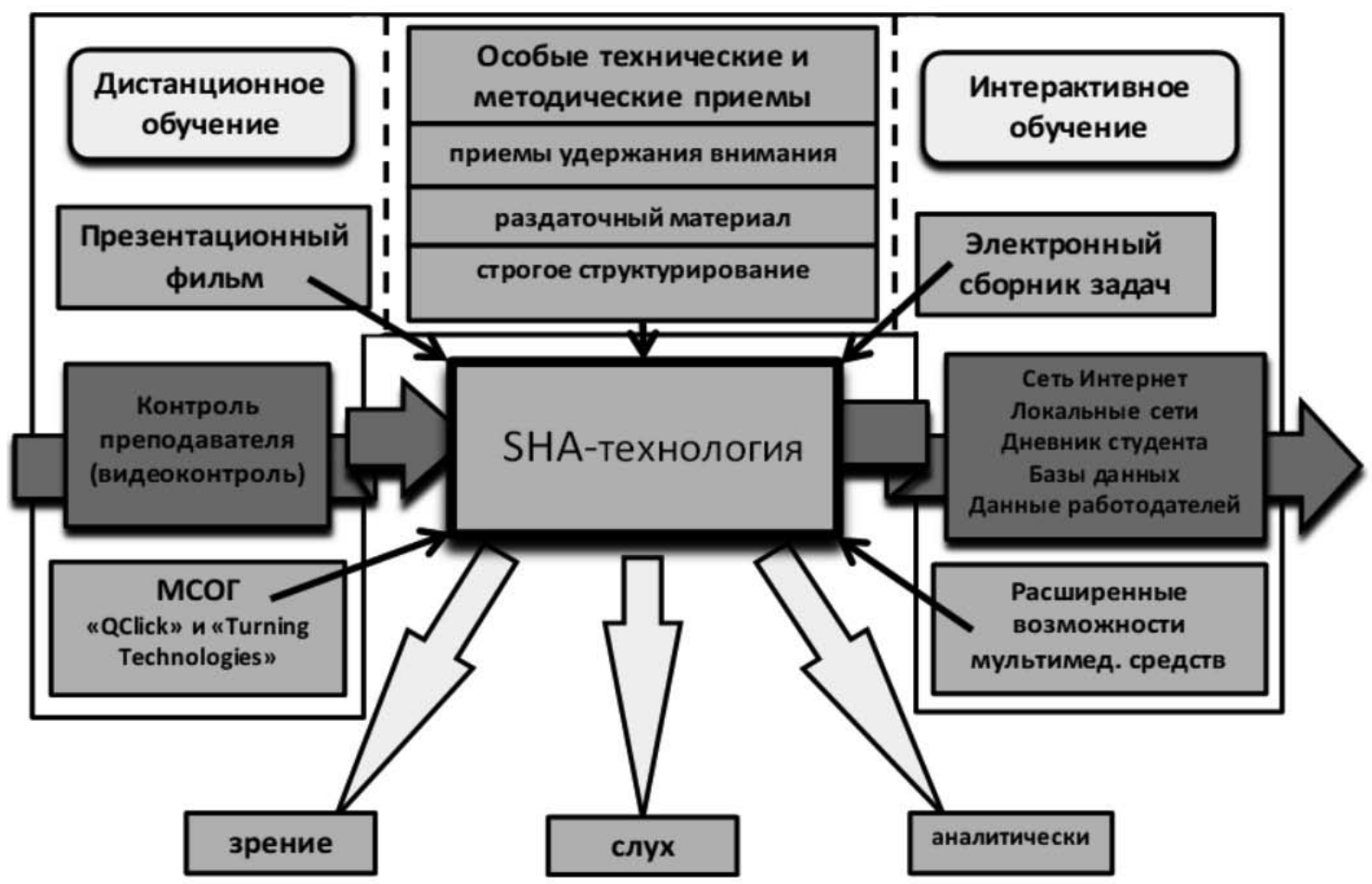

Схема 1. Модель SHA-технологии.

зентационного фильма - это то же отличающее свойство SHA-технологии. Дело в том, что практика проведения занятий с обучающимися в ВУЗе говорит нам о необходимости сменять их внимание каждые 25-30 минут занятия. С этой целью в подготавливаемую презентацию заранее преподавателем включаются соответствующие технические и методические приемы. В качестве таких приемов возможно цитирование высказываний великих людей истории, приведение «шокирующей» статистики, доведение мнения преподавателя на те или иные актуальные (популярные) процессы, короткие видеоролики из практики специализации. В особых случаях это может быть юмор или даже физическая гимнастика. Систематичность таких приемов на подобном занятии должна быть несколько чаще, чем на традиционном занятии.

Самой важной составляющей презентации для еще более продуктивного усвоения информации обучающимися является аудио комментирование слайдов преподавателем. В этом случае, преподавателю необходимо более тщательно подбирать комментирующие и разъясняющие фразы, стремиться избегать глубоких причастных и деепричастных оборотов, длинных по смыслу предложений, способствующих быстрой усталости внимания слушателя.

В контексте рассмотрения образовательных интерактивных технологий, следует упомянуть и мобильные системы опроса и голосования «QClick» и «Turning Technologies». В настоящее время это достаточно популярные среди педагогов высшей школы системы.
Каждая из них представляет из себя комплекс многофункциональных индивидуальных опросных пультов по средствам, которых каждый обучающийся студент имеет возможность оперативно пройти тестирование как в ходе занятия, так и в часы самостоятельной подготовки и получить индивидуальную оценку своих знаний. Подобные системы прекрасно себя зарекомендовали в сочетании с SHA-технологией.

При наличии возможности у преподавателя, эффективным будет прием распространения раздаточного материала, содержание которого, в случае применения рассматриваемой технологии, возможно, формировать, как по желанию обучающегося (путем распечатки в режиме реального времени необходимого материала прямо с автоматизированного рабочего места студента), так и на усмотрение педагога заблаговременно. В последнем случае раздаточный материал необходимо выдавать студентам в начале занятия.

Вообще, выдача обучающимся раздаточного материала - это в некоторой степени прием знаково-контекстного обучения, предполагающего освоение материала студентом в виде учебных текстов как знаковых систем, ускоряющих усвоение материала.

Но отличием, предлагаемым именно автором статьи технологии обучения, является строгая структуризация материала, в том числе в виде задач и проблемных ситуаций, в которых студенту подается его будущая профессия. Такая технология обучения активно прорабатыва- 
лась А.А. Вербецким [2, с. 90].

Уже практически самостоятельным направлением в развитии образовательных технологий современного ВУЗа следует считать создание электронных сборников задач, о которых автор уже упоминал выше. В такие разработки целесообразно включать прикладные и исследовательские задачи, задачи по разрешению кризисных (критических) ситуаций.

Ближайшей перспективой в образовании, а в некоторых ВУЗах уже в настоящем, возможно, считать и электронный дневник студента. Такой вид документа позволит дистанционно, актуально, прозрачно, а самое главное оперативно анализировать успеваемость и учебно-познавательную деятельность индивидуально каждого студента и академической группы в целом. Это будет способствовать оперативному и обоснованному принятию необходимых организационных решений со стороны административно-управленческого персонала ВУЗа, факультета, кафедры, а также и со стороны преподавателя.

Рассматривая современные наиболее популярные образовательные технологии, следует обратить внимание на еще одну остающуюся всегда актуальной технологию - игровую. Как уже многие понимают, игровые образовательные технологии предполагают организацию педагогического процесса с ясной и конкретно сформированной целью обучения студентов и соответствующим этой цели предполагаемым результатом обучения. При этом результат, в основном, явно виден [2, с. 94]. Такое целеполагание игровой технологии остается и по сей день и с течением времени, а также под действием все более ужесточающихся требований от социального заказа не меняется. Однако, достаточно очевидно, что ее подача в подготовке специалистов сильно изменилась. Теперь это может быть розыгрыш какой-либо ситуации с применением программ моделирования; индивидуальные, групповые, а также имитирующие деятельность в группе тренировки; все чаще это и тренинги с применением разных образовательных платформ; конечно же это и игровые технологии с применением эффекта «виртуальной реальности» и 3d-конструирования. В ряде ВУЗов страны уже некоторое время существует требование к преподавателю, согласно которому ему необходимо обязательно погружать обучающегося в смоделированную (им же или компьютером) обстановку в начале каждого занятия, а входе самого занятия условия обстановки постоянно менять - такой методический прием, по мнению автора, целесообразен, конечно же, не во всех ВУЗах, однако, его подобная игровая подача в достаточной мере эффективна. Все приведенные форматы игровой технологии активно задействуются в современной высшей школе. Автор убежден в том, что и в ближайшей перспективе целеполагание игровых технологий обучения если и изменятся, то крайне незначительно, а вот формат реализации такой «игры» будет только развиваться.

Вообще, проблема игровой деятельности в педагогике разрабатывалась уже давно К.Д. Ушинским, С.Л. Рубинштейном, П.П. Блонским и другими.

В их исследованиях подчеркивалось значительно положительное влияние процесса игры в развитии студента, как личности, так и профессионала [2, с. 92]. По мнению исследователей, игра - это мощнейшее средство социализации будущего специалиста в обществе; это возможность предварительной самореализации выпускника ВУЗа; это средство коммуникации студента, дающее ему возможность окунуться в реальную жизненную, служебную атмосферу и выявить при этом свои ошибки.

Приведенные в настоящей статье некоторые примеры образовательных технологий современного ВУЗа, конечно же, не являются самодостаточными, как и отрицающими иные технологий обучения в высшей школе. В статье автор предпринимает попытку закрепить необходимость задействования новых технологий обучения в слиянии их с уже традиционными технологиями и средствами.

Практика задействования рассмотренных в статье современных технологий в учебном процессе ВУЗов свидетельствует об улучшении качества подготовки будущих специалистов. [3, с. 11]. Например, внедрение SHA-технологии в учебный процесс одного из управленческих ВУЗов страны позволило заметно повысить качество усвоения материала потоком обучающихся с использованием комплексной технологии обучения, в сравнении с потоком обучающихся традиционными способами передачи материала.

У каждого педагога годами складывается своя индивидуальная стилистика обучения студентов, которая предполагает, с точки зрения самого педагога, наиболее продуктивный для него труд по воспроизведению знания, передаче его обучающемуся и организации его [знания - авт.] развития в понимании студента. Некоторая доля студентов воспринимает учебный материал в аудиторной форме обучения. Однако, как показывают некоторые исследования, не малая доля обучающихся современных ВУЗов могут эффективно воспринимать учебный материал и в иной форме с применением технологий дистанционного и интерактивного обучения [4, c. 119].

Главенствующим фактором в достижении баланса между указанными формами обучения является направленность задействованной формы на преобладающую самостоятельную учебно-познавательную работу студента. 


\section{ЛИТЕРАТУРА}

1. Бархаев Б.П. Методическое обеспечение преподавания психологии. Учебное пособие. - Москва: ВУ, 2000. - С. 243.

2. Касаткина Н.Э., Градусова Т.К., Жукова Т.А., Кагакина Е.А., Колупаева 0.М., Солодова Г.Г., Тимонина И.В. Современные образовательные технологии в учебном процессе ВУЗа. Методическое пособие. - Кемерово: ГОУ «КРИРПО». 2011. - С. 237.

3. Хохлова 0.Н. Современные образовательные технологии в ВУЗе. Справочник. - Тверь: Твер. гос. ун-т. 2011. - С. 42.

4. Мезенцева 0.И. Современные педагогические технологии. Учебное пособие. - Новосибирск: 000 «Немо Пресс». 2018. - С. 140.

\section{○ Цеханович Денис Борисович (komandor7932@mail.ru).}

Журнал «Современная наука: актуальные проблемы теории и практики»

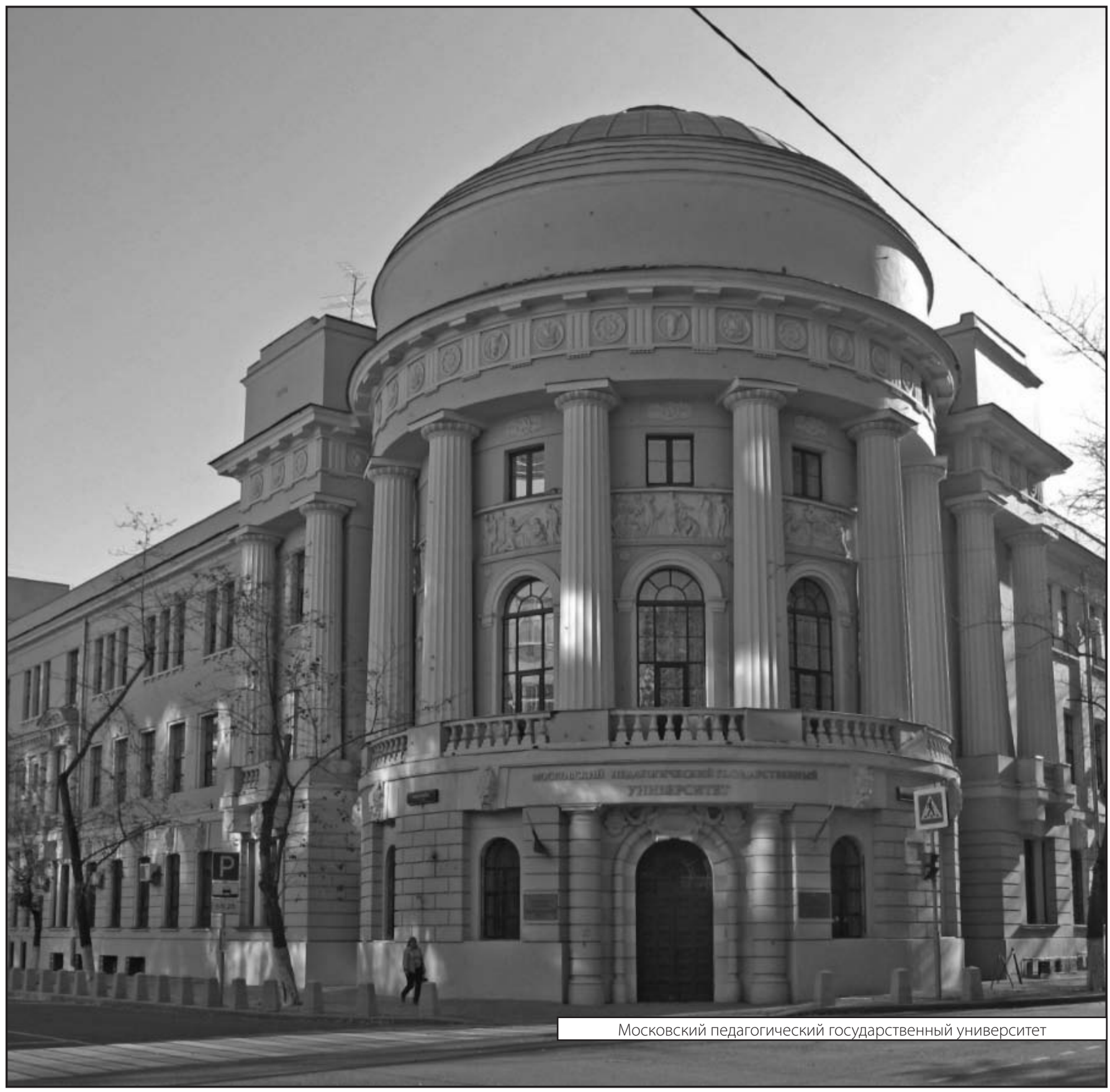

